\title{
Assessing an Interprofessional Polypharmacy and Deprescribing Educational Intervention for Primary Care Post-graduate Trainees: a Quantitative and Qualitative Evaluation
}

\author{
Marcia C. Mecca, MD ${ }^{1,2,3}$, John M. Thomas, $M D^{1,2,4}$, Kristina M. Niehoff, PharmD ${ }^{5,6}$, \\ Anne Hyson, $M D^{7}$, Sean M. Jeffery, PharmD ${ }^{6,7}$, John Sellinger, PhD ${ }^{2,8}$, Adam P. Mecca, MD, PhD', \\ Peter H. Van Ness, PhD ${ }^{1,10}$, Terri R. Fried, MD ${ }^{1,6,10}$, and Rebecca Brienza, MD, MPH ${ }^{1,2}$

\begin{abstract}
'Department of Medicine, Yale School of Medicine, New Haven, CT, USA; ${ }^{2}$ Center of Excellence in Primary Care Education, Veterans Affairs CT, USA; ${ }^{4}$ Dominican House of Studies, Pontifical Faculty of the Immaculate Conception, Washington, DC, USA; ${ }^{5}$ Vanderbilt University Medical Center, Nashville, TN, USA; ${ }^{9}$ Integrated Care Partners, Hartford HealthCare Group, Wethersfield, CT, USA; ${ }^{7}$ University of Connecticut School of Pharmacy, Storrs, CT, USA; ${ }^{8}$ Department of Psychology, Veterans Affairs Connecticut Healthcare System, West Haven, CT, USA; ${ }^{9}$ Department of Psychiatry, Yale School of Medicine, New Haven, CT, USA; ${ }^{10}$ Program on Aging, Yale School of Medicine, New Haven, CT, USA.
\end{abstract} \\ Connecticut Healthcare System, West Haven, CT, USA; ${ }^{3}$ Clinical Epidemiology Research Center, VA Connecticut Healthcare System, West Haven,
}

BACKGROUND: Polypharmacy and potentially inappropriate medications (PIMs) are increasingly common and associated with adverse health effects. However, postgraduate education in polypharmacy and complex medication management for older adults remain limited.

OBJECTIVE: The Initiative to Minimize Pharmaceutical Risk in Older Veterans (IMPROVE) polypharmacy clinic was created to provide a platform for teaching internal medicine (IM) and nurse practitioner (NP) residents about outpatient medication management and deprescribing for older adults. We aimed to assess residents' knowledge of polypharmacy and perceptions of this interprofessional education intervention.

DESIGN: A prospective cohort study with an internal comparison group.

PARTICIPANTS: IM residents and NP residents; Veterans $\geq 65$ years and taking $\geq 10$ medications.

INTERVENTION: IMPROVE consists of a pre-clinic conference, shared medical appointment, individual appointment, and interprofessional precepting model.

MAIN MEASURES: We assessed residents' performance on a pre-post knowledge test, residents' qualitative assessment of the educational impact of IMPROVE, and the number and type of medications discontinued or decreased.

KEY RESULTS: The IMPROVE intervention group ( $n=18$ ) had a significantly greater improvement in test scores than the control group $(n=18)(14 \% \pm 15 \%$ versus $-1.3 \% \pm 16 \%)$ over a period of 6 months (Wilcoxon rank sum, $p=0.019$ ). In focus groups, residents $(n=17)$ reported perceived improvements in knowledge and skills, noting that the experience changed their practice in other clinical settings.

Co-first authors Marcia C. Mecca and John M. Thomas

Prior Presentations 2016 Society of General Internal Medicine Annual Meeting (Poster Presentation), 2017 American Geriatrics Society Annual Meeting (Oral Presentation).

Received June 10, 2018

Revised November 30, 2018

Accepted February 26, 2019

Published online April 10, 2019
In addition, residents valued the unique interprofessional experience. Veterans $(n=71)$ had a median of 15 medications (IQR 12-19), and a median of 2 medications (IQR 1-3) was discontinued. Vitamins, supplements, and cardiovascular medications were the most commonly discontinued medications, and cardiovascular medications were the most commonly decreased in dose or frequency.

CONCLUSIONS: Overall, IMPROVE is an effective model of post-graduate primary care training in complex medication management and deprescribing that improves residents' knowledge and skills, and is perceived by residents to influence their practice outside the program.

KEY WORDS: interprofessional education; geriatrics; polypharmacy; medication management; primary care.

J Gen Intern Med 34(7):1220-7

DOI: $10.1007 / \mathrm{s} 11606-019-04932-9$

(c) Society of General Internal Medicine (This is a U.S. government work and not under copyright protection in the U.S.; foreign copyright protection may apply) 2019

\section{INTRODUCTION}

As the population of Americans aged $\geq 65$ increases, $^{1}$ the number of chronic conditions ${ }^{2}$ and medications used to treat them is rising. ${ }^{3-5}$ In fact, $39 \%$ of patients aged $\geq 65$ take $\geq 5$ medications. ${ }^{3}$ Polypharmacy, the use of multiple medications, is associated with increased risk of falls, adverse drug effects, hospitalizations, and mortality even after adjusting for chronic conditions. ${ }^{6}$ The number of medications is the strongest predictor of potentially inappropriate medication (PIM) use, 5, 7 and PIMs are also associated with adverse outcomes. ${ }^{8,9}$ Furthermore, evidence suggests that deprescribing interventions reduce adverse outcomes such as falls ${ }^{10,11}$ and adverse drug events, ${ }^{12}$ and can improve cognition, ${ }^{13}$ and selfreported health and quality of life. ${ }^{13}$ Efforts to develop effective interventions for deprescribing are growing ${ }^{12,14-16}$ and have the potential to decrease healthcare costs. ${ }^{17}$ 
The Accreditation Council for Graduate Medical Education, American Board of Internal Medicine, American Medical Association, and others support the internal medicine (IM) milestones, ${ }^{18}$ which emphasize the development of comprehensive management plans for complex patients, such as those with polypharmacy. Medication management is also an important component of the recently published competencies in Veteran Affairs (VA) nurse practitioner (NP) residencies in primary care. ${ }^{19}$ Despite a growing recognition of the need for enhanced training for future primary care providers in geriatric care, including training in medication management, ${ }^{20-23}$ such training in post-graduate medical education has been limited nationally. ${ }^{24-26}$ This is supported by IM residents' perceptions of training gaps in prioritizing care in complex patients with polypharmacy. ${ }^{27,}{ }^{28}$ In one study, residents participating in an interprofessional medication management workshop demonstrated modest improvements in reviewing medication lists, and $95 \%$ of participants planned to make changes to their patient's medication regimen after the workshop. ${ }^{28}$ However, with a $55 \%$ attrition rate at 3 months, only $35 \%$ of the participants who followed up reported actually making changes, raising concerns about the challenges of implementing knowledge and skills acquired outside the clinical context.

In response to the need for effective educational experiences in deprescribing, we created an interprofessional educational program called Initiative to Minimize Pharmaceutical Risk in Older Veterans (IMPROVE), which is an innovative clinical training experience in a new polypharmacy clinic within a VA interprofessional academic primary care setting. The aims of this study were to assess the effect of IMPROVE on the following: (1) IM and NP residents' knowledge of PIMs and complex medication management in older adults; (2) residents' perceptions of the intervention's educational impact; and (3) patients' medications.

\section{METHODS}

\section{Setting and Participants}

IMPROVE was developed and implemented by the IMPROVE faculty team, which included an internist, geriatrician, geriatric pharmacist, and psychologist within the VA Connecticut Center of Excellence (COE) in Primary Care Education. The COE is an interprofessional academic patient-centered medical home in primary care that includes IM and NP residents, psychology trainees, and clinical pharmacy residents. IM residents request COE placement when applying to Yale residency, and NPs apply to the COE residency for additional interprofessional primary care training after obtaining licensure.

All of the 17 IM and 4 NP residents in the COE were assigned in a rotating fashion to participate in two to three half-day IMPROVE clinics each, with five residents assigned to each clinic. Each resident evaluated one patient per clinic, with five patients scheduled per clinic. The control group consisted of all $18 \mathrm{IM}$ residents also assigned to the VA but not in the COE. No NP residents were included in the control group because the only NP residents in the region received the intervention. This study was approved by the Human Subjects Committee at Veterans Affairs Connecticut. Waiver of informed consent was granted and no participants received payment.

\section{Educational Intervention Design}

Utilizing Armstrong's adaptation ${ }^{29}$ of the Kolb experiential learning theory, ${ }^{30}$ IMPROVE was designed to maximally impact the learning of residents by including curricular elements from all four steps of the learning cycle. This theoretical framework emphasizes reflection and establishment of personal meaning for learners as the first step. The acquisition of new knowledge and concepts then builds upon established meaning. Practical application solidifies that knowledge, and synthesis and extension of that experience facilitate the use of that knowledge in other experiences. The four components of IMPROVE mirrored these steps in the learning cycle and included (1) resident selection of a Veteran from their panel with polypharmacy and completion of a medication review worksheet ${ }^{31}$ (2) acquisition of new knowledge and concepts during a pre-clinic conference, (3) practical application in the shared medical appointment (SMA) and individual appointment, and (4) synthesizing information with interprofessional team precepting (Fig. 1).

Medication Review Worksheet. Residents identified a Veteran from their panel who met the following criteria: age $\geq 65$ and prescribed $\geq 10$ medications. To prepare for the clinic, residents reviewed the chart and completed a medication review worksheet (available at https://www.pogoe.org/ productid/21872). ${ }^{31}$ The worksheet prompted analysis of the regimen using a series of analytical questions with hyperlinks to published tools, ${ }^{32-36}$ guidelines, ${ }^{37-40}$ and calculators ${ }^{41-44}$ to inform the development of a deprescribing strategy.

Pre-clinic Conference. During a 60-min pre-clinic conference at the beginning of each clinic, residents discussed their worksheets and deprescribing strategies with IMPROVE faculty, pharmacy residents, and other participating residents, and modified them if needed. In addition to knowledge gained through these discussions, residents also participated in a 20min interactive discussion of a specific deprescribing concept. These topic discussions ${ }^{45}$ were led by a pharmacist, geriatrician, or health psychologist and included deprescribing tools $^{32,34}$ as well as reviews of specific medication classes or disease states focused on treatment indications, duration, adverse effects, and discontinuation strategies. Alternative evidence-based pharmacologic and non-pharmacologic therapies were also included if applicable.

SMA and Individual Provider Appointment. With assistance from a pharmacy resident and/or psychology trainee, residents 


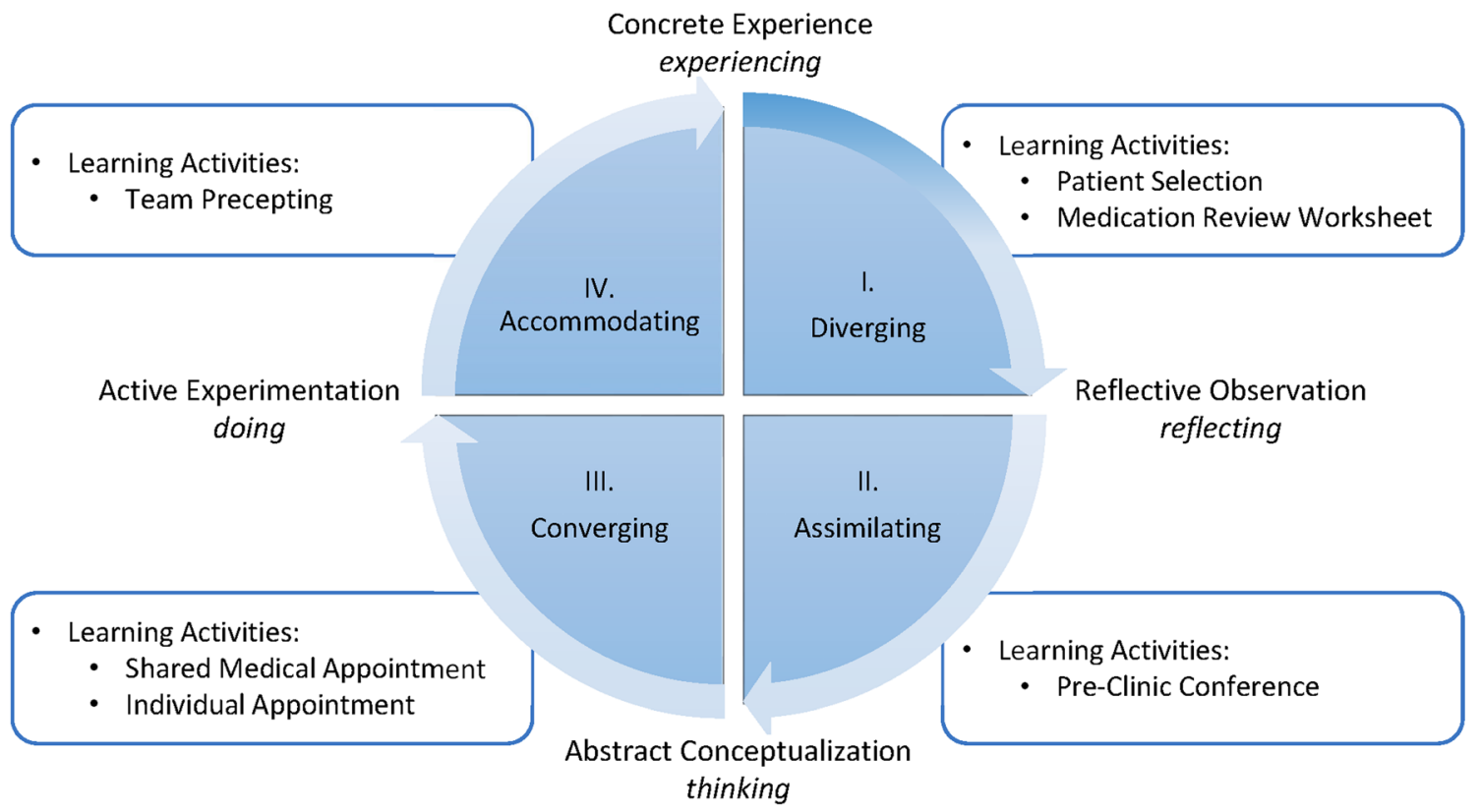

Figure 1 Initiative to Minimize Pharmaceutical Risk in Older Veterans educational intervention design using experiential learning theory. Intervention learning activities are mapped to the learning cycle outlined by Armstrong's adaptation ${ }^{29}$ of the Kolb experiential learning theory. ${ }^{30}$

rotated leading the 30-min SMA using a discussion content guide ${ }^{45}$ meant to elicit Veteran concerns about their medications and provide relevant patient education. Five Veterans were scheduled for each SMA. Each resident then had a 60min individual visit with their patient and the patient's caregiver (if applicable). During the individual visit, residents completed the IMPROVE patient questionnaire ${ }^{45}$ and thorough medication reconciliation. To inform deprescribing, they also performed orthostatic vital signs and a Saint Louis Mental Status Examination (nb capitalize as this is the formal name of the test). ${ }^{46}$ Orthostatic hypotension prompted reductions in antihypertensives and impairments in cognition guided patient education about adherence strategies as well as efforts to deprescribe psychotropic medications where possible.

IMPROVE Team Precepting. Residents were precepted by the interprofessional IMPROVE team (internist or geriatrician, pharmacist, and psychologist, if applicable). Residents discussed any medication changes with patients, including risks and benefits as well as specific discontinuation strategies (e.g., tapering). Finally, residents were responsible for discussing the treatment plan with subspecialists or other providers, coordinating treatment plans with the Veteran and family, and completing the IMPROVE note.

The IMPROVE resources are available at http://improvepolypharmacy.yale.edu. ${ }^{45}$

\section{Data Collection and Analysis}

This exploratory, sequential mixed methods study included both quantitative analysis of the effect of IMPROVE on resident knowledge and the effect on Veteran medication regimens. Qualitative methods were utilized to provide additional insight into quantitative results and to explore additional impact on residents not captured by quantitative methods.

Knowledge Assessment. IM and NP residents were asked to complete a 26-item multiple choice polypharmacy knowledge test twice over the course of the study. Each resident chose an alphanumeric identification code, known only to that individual, to label his or her two tests. The assessment was completed by the intervention group both before participation (baseline) and at 6-month follow-up. The control group of IM residents was tested at the same time interval. To accommodate all IM residents, whose ambulatory rotations fall into one of two scheduling groups, we held two baseline testing sessions for the intervention group and two baseline testing sessions for the control group. This process was repeated so that each resident completed the follow-up test at 6 months from baseline. This testing process occurred between December 2014 and June 2015. While they were involved in aspects of the clinic, health psychology trainees were not tested because they do not prescribe medications, and pharmacy residents were not tested because they were considered content experts. A 12-item version of this test was previously validated for distinguishing different levels of knowledge within a single domain of polypharmacy that emphasized optimal medication management in older adults (available at https://www.ajpe.org/doi/pdf/10.5688/ ajpe6435) ${ }^{47}$ Test scores for the validated 12 -item test were extracted from the original 26 -item version and used to compare the change in test performance over time in the two groups. Because change in test scores was ordinal and not normally distributed (Lilliefors test), a non- 
parametric method was used to compare the differences between groups (Wilcoxon rank sum). Group score changes are reported as mean \pm standard deviation.

Veteran Medication Regimens. Veteran characteristics were compiled from IMPROVE questionnaires ${ }^{45}$ and chart review at the time of the SMA and individual visit. The number of diagnoses among 15 common chronic conditions was tabulated and summed for each Veteran. The number of medications was determined from a thorough medication reconciliation at the beginning of the individual visit and the number of medications decreased and discontinued at the visit was also counted. Supplies (e.g., glucose test strips, bandages), ophthalmic agents, and topical moisturizing agents were not included in medication counts. Inhalers and all other medications were included in medication counts. Discontinued and decreased medications were coded into specific drug classes and then grouped into broad categories by organ system. For the number of common chronic conditions and the number of medications, median and interquartile range (IQR) were calculated.

Residents' Perceptions of Impact. Intervention residents were invited to participate in two focus groups to characterize the perceived impact of IMPROVE on knowledge, skills, attitudes, and behaviors. To minimize social desirability bias, participation was anonymous. The interviews were facilitated by a trained researcher, who asked open-ended questions using a discussion guide to ensure a standardized approach. The interviewer was not involved in the intervention design or implementation to further minimize social desirability bias. The focus groups were audiotaped and professionally transcribed.

Content analysis was used to analyze the transcripts. ${ }^{48}$ Three analysts (MM, JT, KN) independently reviewed the focus group transcripts, identified unique conceptual codes, and developed a coding structure. Codes were assigned based on repeated close readings of the text. They then met to compare the coding structures and their application to the text. Differences were resolved through discussion until consensus was achieved. The three analysts discussed the relationships of the codes within and across transcripts to identify higher-order themes of trainee resident perceptions about the impact of participation in IMPROVE. This analysis was repeated, reviewed, and confirmed by a psychologist and qualitative researcher uninvolved in the design or implementation of IMPROVE.

\section{RESULTS}

\section{Knowledge Assessment}

In the intervention group, 21 residents were eligible for the baseline test and 18 (14 IM and $4 \mathrm{NP}$ ) completed the test $(85.7 \%, 18 / 21)$. At the 6-month follow-up, 16 residents (14 IM and $4 \mathrm{NP})$ completed the test $(76.2 \%, 16 / 21)$. In the control group, $18 \mathrm{IM}$ and no NP residents completed the baseline test, out of 18 eligible IM residents and no eligible NP residents. Thirteen of these completed the 6-month follow-up (72.2\%, 13/18). The intervention group had a mean score of $63 \% \pm$ $16 \%$ at baseline and $76 \% \pm 17 \%$ at follow-up. The control group had a mean score of $65 \% \pm 18 \%$ at baseline and $64 \% \pm$ $15 \%$ at follow-up (Fig. 2). There were no differences in test performance between groups at baseline (Wilcoxon rank sum, $p=0.253)$. The intervention group $(+14 \% \pm 15 \%)$ had a significantly greater improvement in test score than the control group $(-1.3 \% \pm 16 \%)$ over the same period (Wilcoxon rank sum, $p=0.019)$.

\section{Veteran Medications}

Baseline characteristics of Veterans participating in IMPROVE clinic are shown in Table 1. Of the 71 Veterans evaluated, 59\% were 65-74 years old, $23 \%$ were $75-$ 84 years old, and $18 \%$ were $\geq 85$ years old (median 71 ). The sample was almost entirely male (97\%). The median number of chronic conditions was 4 (IQR 3-5). Hypertension, diabetes, and coronary artery disease were the most common chronic conditions. Veterans were taking a median of 15 medications (IQR 12-19) on presentation to the clinic after medication reconciliation. Medications were discontinued in $85 \%$ of Veterans, with $20 \%$ discontinuing 1 medication, $32 \%$ discontinuing 2 medications, and $32 \%$ discontinuing 3 or more medications. Medications were decreased in dose or frequency in $49 \%$ of Veterans, with $32 \%$ decreasing 1 medication, $11 \%$ decreasing 2 medications, and $5.6 \%$ decreasing 3 or more medications. Of the 152 total medications discontinued (Table 2), vitamins and supplements $(41 \%)$ were the most common class, followed by cardiovascular (18\%) and pulmonary/allergy (9.2\%) medications. Of the 52 medications decreased in dose or frequency, cardiovascular medications were the most common class (47\%), followed by neuropsychiatric $(16 \%)$ and urologic $(10 \%)$ medications.

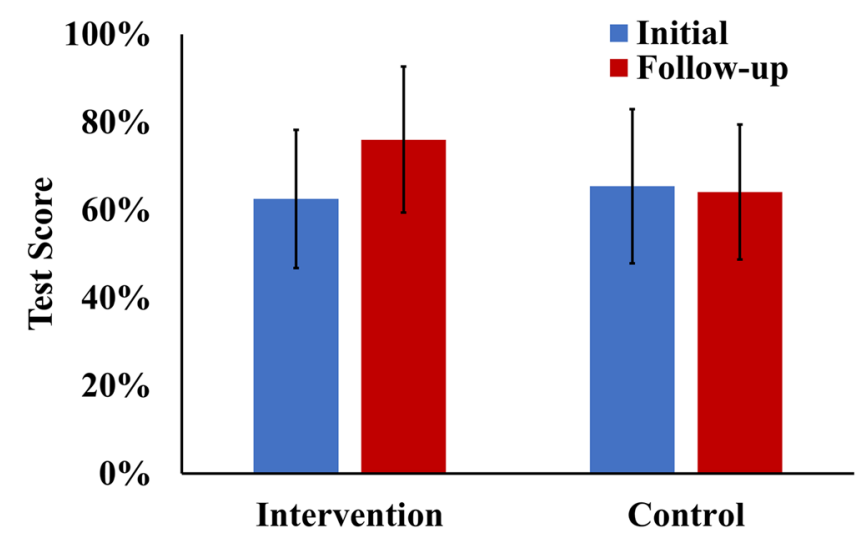

Figure 2 Performance on 12-item knowledge test. Blue bars indicate the mean test score at baseline for each group and red bars indicate the mean score at 6-month follow-up. Error bars represent standard deviation. 


\section{Residents' Perceptions of Impact}

Seventeen IM and NP residents participated in the two focus groups (81\% participation rate, 17/21). Four themes emerged that were present in both focus groups and that represent resident perceptions of the impact of participating in IMPROVE.

Recognition of Trade-offs in Medication Prescribing. Residents perceived that the program helped them to appreciate the inherent trade-offs involved in prescribing, and that such decisions involve patient preferences that may change over time: "It has made me think that the medications all have trade-offs, risks, and benefits, and maybe it's not an easy decision for the patient ... to discontinue a medication, and that decision may change."

Acquisition of Knowledge and Skills. Residents identified several ways in which they gained knowledge and skills through the program. They perceived that the program filled an important knowledge gap in their training in polypharmacy and geriatric medicine: "Since we don't have much training in polypharmacy or geriatric medicine, [IMPROVE] has been helpful both with my patients and in the hospital as well." They stated that they learned a systematic approach to reviewing the medications: "Polypharmacy [clinic] forces you to go through the medications list in a systematic way." They also reported a greater adeptness in consulting specialists

Table 1 Baseline Characteristics of Patients Participating in IMPROVE

\begin{tabular}{ll}
\hline \hline $\boldsymbol{N}=\mathbf{7 1}$ & $\begin{array}{l}\text { Count (\%) or } \\
\text { median (IQR) }\end{array}$ \\
\hline Age, median (IQR) & $71(68-81)$ \\
Male & $69(97)$ \\
Number of medications, median (IQR) & $15(12-19)$ \\
Common chronic conditions, median (IQR) & $4(3-5)$ \\
Atrial fibrillation & $16(23)$ \\
Benign prostatic hyperplasia & $21(30)$ \\
Chronic kidney disease & $10(14)$ \\
Chronic obstructive pulmonary disease & $18(25)$ \\
Congestive heart failure & $16(23)$ \\
Coronary artery disease & $30(43)$ \\
Diabetes & $41(58)$ \\
Gastroesophageal reflux disease & $27(38)$ \\
History of cancer & $11(16)$ \\
History of myocardial infarction & $7(10)$ \\
History of stroke & $14(20)$ \\
Hypertension & $55(78)$ \\
Hypothyroidism & $9(13)$ \\
Osteoarthritis & $16(23)$ \\
Peripheral artery disease & $3(4)$ \\
Self-rated general health, fair or poor & $25(35)$ \\
Self-rated quality of life, fair or poor & $21(29)$ \\
Dependence in at least one activity of & $36(51)$ \\
daily living or instrumental activity & \\
of daily living & \\
One fall in the past 3 months & $11(16)$ \\
Two or more falls in the past 3 months & $14(20)$ \\
At least one hospitalization in the past 3 months & $17(24)$ \\
SLUMS examination, < 24/30 & $31(44)$ \\
\hline
\end{tabular}

IMPROVE, Initiative to Minimize Pharmaceutical Risk in Older Veterans; IQR, interquartile range (25th-75th percentile); SLUMS, Saint Louis University Mental Status $(<24 / 30$ is consistent with cognitive impairment) ${ }^{4 \sigma}$ regarding medication management: "It's a really coherent story and it's an informed consult that's useful to our specialists who are also trying to piece together this history."

Change of Practice. Many examples were provided by residents of perceived changes in their clinical practice based on what they learned in IMPROVE clinic (Table 3). These changes included reviewing medications lists more proactively and attentively, finding clinical successes in other patients, applying skills learned to the inpatient setting, and being more attentive to possible adverse effects of medications.

Table 2 Categories of Medications Discontinued or Decreased During IMPROVE

\begin{tabular}{|c|c|c|}
\hline Medication & $\begin{array}{l}\text { Medications } \\
\text { discontinued, } \\
\text { count }(\%)\end{array}$ & $\begin{array}{l}\text { Medications } \\
\text { decreased in dose } \\
\text { or frequency, count } \\
(\%)\end{array}$ \\
\hline Vitamins/supplements & $62(41)$ & $2(3.8)$ \\
\hline Vitamin/mineral & $42(28)$ & $2(3.8)$ \\
\hline Supplement & 21 (14) & $0(0)$ \\
\hline Cardiovascular & $28(18)$ & $24(46)$ \\
\hline Antianginal & $2(1.3)$ & $0(0)$ \\
\hline Antiarrhythmic & $2(1.3)$ & $0(0)$ \\
\hline Anticoagulant & $1(1)$ & $4(7.7)$ \\
\hline Antihypertensive & $11(7.2)$ & $19(37)$ \\
\hline Antilipemic & $9(5.9)$ & $1(1.9)$ \\
\hline Antiplatelet & $1(0.7)$ & $0(0)$ \\
\hline Cardiac glycoside & $2(1.3)$ & $0(0)$ \\
\hline Pulmonary and allergy & $14(9.2)$ & $1(1.9)$ \\
\hline Antihistamine & $10(6.6)$ & $1(1.9)$ \\
\hline Antitussive & $1(0.7)$ & $0(0)$ \\
\hline Inhaled corticosteroid/ & $1(0.7)$ & $0(0)$ \\
\hline beta agonist & & \\
\hline Corticosteroid & $2(1.3)$ & $0(0)$ \\
\hline Gastrointestinal & $12(7.9)$ & $4(7.7)$ \\
\hline Antacid & $9(5.9)$ & $3(5.8)$ \\
\hline Bowel medication & $3(2.0)$ & $1(1.9)$ \\
\hline Neuropsychiatric & $11(7.2)$ & $9(17)$ \\
\hline $\begin{array}{l}\text { Acetylcholinesterase } \\
\text { inhibitor }\end{array}$ & $2(1.3)$ & $0(0)$ \\
\hline Antidepressant & $4(2.6)$ & $2(3.8)$ \\
\hline Barbiturate & $0(0.0)$ & $1(1.9)$ \\
\hline Benzodiazepines/ & $4(2.6)$ & $3(5.8)$ \\
\hline hypnotics & & \\
\hline Antineuropathic pain & $1(0.7)$ & $2(3.8)$ \\
\hline Dopamine agonist & $0(0.0)$ & $1(1.9)$ \\
\hline Endocrine & $10(6.6)$ & $3(5.8)$ \\
\hline Antidiabetic & $6(3.9)$ & $3(5.8)$ \\
\hline Bisphosphonate & $2(1.3)$ & $0(0)$ \\
\hline Hormone & $2(1.3)$ & $0(0)$ \\
\hline Urologic & $6(3.9)$ & $5(9.6)$ \\
\hline Alpha antagonists & $3(2.0)$ & $4(7.7)$ \\
\hline Antispasmodic & $2(1.3)$ & $1(1.9)$ \\
\hline Prostaglandin E1 & $1(0.7)$ & $0(0)$ \\
\hline Musculoskeletal/ & $7(3.9)$ & $4(7.7)$ \\
\hline Prescription analgesic & $2(1.3)$ & $1(1.9)$ \\
\hline Skeletal muscle & $1(0.7)$ & $2(3.8)$ \\
\hline relaxant & & \\
\hline Folate antagonist & $1(0.7)$ & $0(0)$ \\
\hline $\begin{array}{l}\text { Xanthine oxidase } \\
\text { inhibitor }\end{array}$ & $2(1.3)$ & $1(1.9)$ \\
\hline Topical analgesic & $1(0.7)$ & $0(0)$ \\
\hline Infectious disease & $2(1.3)$ & $0(0)$ \\
\hline Antibacterial cream & $1(0.7)$ & $0(0)$ \\
\hline Antibiotic & $1(0.7)$ & $0(0)$ \\
\hline Total & 152 & 52 \\
\hline
\end{tabular}

IMPROVE, Initiative to Minimize Pharmaceutical Risk in Older Veterans 
Table 3 How Residents Perceive IMPROVE Changed Their Clinical Practice

\begin{tabular}{|c|c|}
\hline Change of practice & Representative quotation \\
\hline $\begin{array}{l}\text { Reviewing medications lists } \\
\text { more proactively and } \\
\text { attentively }\end{array}$ & $\begin{array}{l}\text { "I am more proactive about looking } \\
\text { at the medication list, especially [for] } \\
\text { the older ones." } \\
\text { "I think I am definitely more aware } \\
\text { of making sure that with all of my } \\
\text { patients, I am looking more closely at } \\
\text { their medication list, and I think the } \\
\text { educational sessions beforehand do } \\
\text { give us a better sense of, these are } \\
\text { some drugs ... that you should be } \\
\text { thinking about. So, it has certainly } \\
\text { changed the wav I approach it." }\end{array}$ \\
\hline $\begin{array}{l}\text { Finding clinical successes in } \\
\text { other patients }\end{array}$ & $\begin{array}{l}\text { "I have been using tapering of } \\
\text { [proton pump inhibitors] and initially } \\
\text { it was unsuccessful because I did not } \\
\text { know you needed to taper it and they } \\
\text { all restarted their symptoms and now } \\
\text { I have gotten I think three different } \\
\text { patients off of [them by tapering]." }\end{array}$ \\
\hline $\begin{array}{l}\text { Applying skills learned to the } \\
\text { inpatient setting }\end{array}$ & $\begin{array}{l}\text { "One of the things I found is that a } \\
\text { lot of ... the skills I learned in } \\
\text { IMPROVE I take to the inpatient side } \\
\text { of the hospital." }\end{array}$ \\
\hline $\begin{array}{l}\text { Being more attentive to } \\
\text { possible adverse effects }\end{array}$ & $\begin{array}{l}\text { "And those principles that we learn } \\
\text { during those sessions, I mean also the } \\
\text { pharmacists do give us like a small } \\
\text { learning session, say for the last visit } \\
\text { we did beta blockers in class and } \\
\text { then their side effects ... I use them } \\
\text { outside the IMPROVE clinic." }\end{array}$ \\
\hline
\end{tabular}

IMPROVE, Initiative to Minimize Pharmaceutical Risk in Older Veterans

Value of Interprofessional Training. Residents believed that the interprofessional aspect of the program was valuable. For instance, they valued the interprofessional aspect of clinical precepting: "I wish there were more opportunities to co-precept with the geriatrician and the pharmacist because I could use that on a daily basis with most of my patients." They also found the pre-clinic conference beneficial: "The small group of providers just meeting together [at the] beginning to discuss all of the patients also helped me." Many residents wished to have more time allocated for the pre-clinic conference: "I would like to have more time when we actually went through each person's individual medication list ... I learned so much from that experience." Finally, they were encouraging of interprofessional involvement in leading the SMA: "I do like the role of pharmacy and health psychology [co-]leading the group."

\section{DISCUSSION}

In this innovative interprofessional educational program aimed at teaching IM and NP residents how to effectively evaluate and manage complex medication regimens for older adults in the outpatient setting, we found evidence that resident participation in the program builds knowledge of polypharmacy and complex medication management over nonparticipating residents. Moreover, residents reported that the program was a valuable educational experience for them. They expressed a greater appreciation for the inherent complexity of deprescribing for older adults, and they perceived improvements in their knowledge and skills that led to a change of practice beyond the program itself, extending into the inpatient and outpatient settings. Residents valued the interprofessional aspect of the program, advocating for more interprofessional involvement in their clinical experiences. All Veterans participating in the program had multiple chronic conditions and significant polypharmacy, but were able to reduce the number, dose, and/or frequency of medications.

To our knowledge, our study is the most comprehensive educational intervention seeking to equip IM and NP residents with the knowledge, skills, and attitudes to address polypharmacy for older adults in the outpatient setting. In this way, the IMPROVE program provides a response to the general call for training future primary care providers in medication management for older adults. ${ }^{20-23}$ Our findings from knowledge testing and focus group interviews further confirm the need for more education in geriatrics and pharmacology for residents. Resident feedback suggests that they not only positively received the addition, but they also asked for more opportunities to focus on these aspects of their clinical education.

There are several notable features of our program. For one, it is embedded in an interprofessional academic primary care clinic, allowing for the integration of educational activities and collaborative direct patient care for residents rotating through the clinic. Many previous efforts to educate residents in safe prescribing for the elderly have been lecture- or seminarbased. ${ }^{21,28}$ Also, our program promotes a systematic approach to medication review and deprescribing that allows residents to operationalize available tools and the latest evidence. ${ }^{31,32,34} \mathrm{To}$ optimize resident learning, we incorporated the elements of experiential learning theory into the clinic design. ${ }^{29,}{ }^{30}$ Finally, our program is interprofessional in the makeup of both faculty and residents, allowing for a rich educational experience that draws upon complementary clinical roles and areas of expertise. Such an educational design may be valuable for addressing the complex issue of medication management in older adults, especially given the need for increased educational interventions for both residents and attendings in primary care. ${ }^{47}$

The findings of our study can be most readily compared to those of a prior study that applied a systematic approach to discontinuing medications for older adults in a non-academic outpatient setting. ${ }^{13}$ In our study, the average number of medications was 16.2 per patient $(n=71)$, and an average of 2.1 medications were discontinued. In the prior study, the average number of medications was 7.7 per patient $(n=70)$, and an average of 4.2 medications were discontinued. Differences in demographics and comorbidities may account for some of these differences. For instance, our study cohort was younger on average ( 74 years versus 83 years); had a higher rate of hypertension ( $78 \%$ versus $63 \%$ ), diabetes ( $58 \%$ versus $33 \%$ ), and coronary artery disease ( $43 \%$ versus $30 \%$ ); and was less physically impaired (20\% recurrent falls versus $50 \%$ ). Based on these differences, it may be that the patients in our study had more indications for medications, and were better 
able to tolerate them, than the patients of the prior study. The residents in our study expressed an awareness of the inherent trade-offs in prescribing, suggesting that such considerations factored significantly in decision making. Patients have also expressed an awareness of such trade-offs. ${ }^{49}$

There were some limitations to this study. Given the modest total number of residents participating in the IMPROVE program, it is unclear what effects the program would have if implemented on a larger scale. All residents in the intervention group had elected to conduct their training in an interprofessional patient-centered medical home, introducing the possibility of selection bias. To minimize this bias, our comparison group consisted of residents assigned to the same VA site for primary care training outside the COE. In addition, there were no baseline differences in knowledge test performance, suggesting similar aptitudes for polypharmacy knowledge between groups. Additionally, the residents' views expressed in the focus groups may have been subject to social desirability bias, although efforts were taken to minimize this. Finally, additional work is needed to determine the successfulness of the clinical intervention itself. This includes evaluating the safety and stability of medication discontinuation over time.

Our findings suggest that the IMPROVE educational intervention was a valuable interprofessional learning experience for residents, increased knowledge of polypharmacy and deprescribing, and was perceived by residents to change their clinical practice outside of the program. More research is needed to determine the long-term clinical effects of the program on patients, the objective effects on deprescribing behaviors, and the feasibility of implementing the program on a larger scale. As an interprofessional model for clinical training in complex medication management for older adults, IMPROVE may be helpful in preparing future primary care providers to care for older adults.

Acknowledgments: The authors would like to acknowledge and thank Elizabeth Armstrong, Ph.D. and the Harvard Macy Institute, as well as Lauretta Grau, PhD, for her skillful assistance with the coding of manuscripts, and Destiny Printz, for her skillful conducting of focus group interviews.

Corresponding Author: Marcia C. Mecca, MD; Clinical Epidemiology Research Center, VA Connecticut Healthcare System, 950 Campbell Avenue, West Haven, CT, USA (e-mail: marcia.mecca@yale.edu).

Funders This work was supported in part by the Veteran Affairs Office of Academic Affiliations (COEPCE), VA Connecticut Healthcare System, John A. Hartford Foundation (Center of Excellence Geriatric Scholar Award), the Yale Claude D. Pepper Older Americans Independence Center at Yale University School of Medicine (P3OAG021342 NIH/NIA), the National Institute of Mental Health (5R25MHO7158407), and an award from Health Resources and Services Administration Geriatric Workforce Enhancement Program to Yale University School of Medicine (U1BHP28745).

\section{Compliance with Ethical Standards:}

This study was approved by the Human Subjects Committee at Veterans Affairs Connecticut. Waiver of informed consent was granted and no participants received payment.
Conflict of Interest: Dr. Jeffery is a consultant for CVS Caremark. All remaining authors declare that they do not have a conflict of interest.

Disclaimer: This material is the result of work supported with resources and the use of facilities at the VA Connecticut. The contents do not represent the views of the U.S. Department of Veterans Affairs or the United States Government.

\section{REFERENCES}

1. Mather M, Jacobsen L, Pollard K. Aging in the United States. Popul Bull. 2015;70(2).

2. Wolff JL, Starfield B, Anderson G. Prevalence, expenditures, and complications of multiple chronic conditions in the elderly. Arch Intern Med. 2002;162(20):2269-2276.

3. Kantor ED, Rehm CD, Haas JS, Chan AT, Giovannucci EL. Trends in prescription drug use among adults in the united states from 1999-2012. JAMA. 2015;314(17):1818-1830.

4. Gato DM, Wilder J, Schumm LP, Gillet V, Alexander GC. Changes in Prescription and Over-the-Counter Medication and Dietary Supplement Use Among Older Adults in the United States, 2005 vs 2011. JAMA Intern Med 2016;176(4):473-482.

5. Steinman MA, Miao Y, Boscardin WJ, Komaiko KD, Schwartz JB. Prescribing quality in older veterans: a multifocal approach. J Gen Intern Med 2014;29(10):1379-1386.

6. Fried TR, O'Leary J, Towle V, Goldstein MK, Trentalange M, Martin DK. Health outcomes associated with polypharmacy in communitydwelling older adults: a systematic review. J Am Geriatr Soc. 2014;62(12):2261-2272

7. Jiron M, Pate V, Hanson LC, Lund JL, Jonsson Funk M, Sturmer T. Trends in Prevalence and Determinants of Potentially Inappropriate Prescribing in the United States: 2007 to 2012. J Am Geriatr Soc. 2016;64(4):788-797.

8. Fick DM, Mion LC, Beers MH, J LW. Health outcomes associated with potentially inappropriate medication use in older adults. Res Nurs Health. 2008;31(1):42-51.

9. Stockl KM, Le L, Zhang S, Harada AS. Clinical and economic outcomes associated with potentially inappropriate prescribing in the elderly. Am J Manag Care. 2010;16(1):e1-10.

10. Tinetti ME, Baker DI, McAvay G, et al. A multifactorial intervention to reduce the risk of falling among elderly people living in the community. $\mathrm{N}$ Engl J Med. 1994;331(13):821-827.

11. van der Cammen TJ, Rajkumar C, Onder G, Sterke CS, Petrovic M. Drug cessation in complex older adults: time for action. Age Ageing. 2014;43(1):20-25.

12. Gnjidic D, Le Couteur DG, Kouladjian L, Hilmer SN. Deprescribing trials: methods to reduce polypharmacy and the impact on prescribing and clinical outcomes. Clin Geriatr Med. 2012;28(2):237-253.

13. Garfinkel D, Mangin D. Feasibility study of a systematic approach for discontinuation of multiple medications in older adults: addressing polypharmacy. Arch Intern Med. 2010;170(18):1648-1654.

14. Niehoff KM, Rajeevan N, Charpentier PA, Miller PL, Goldstein MK, Fried TR. Development of the Tool to Reduce Inappropriate Medications (TRIM): A Clinical Decision Support System to Improve Medication Prescribing for Older Adults. Pharmacotherapy. 2016;36(6):694-701.

15. Tannenbaum C, Martin P, Tamblyn $\mathbf{R}$, Benedetti A, Ahmed S. Reduction of inappropriate benzodiazepine prescriptions among older adults through direct patient education: the EMPOWER cluster randomized trial. JAMA Intern Med. 2014;174(6):890-898.

16. Scott IA, Hilmer SN, Reeve E, et al. Reducing inappropriate polypharmacy: the process of deprescribing. JAMA Intern Med. 2015;175(5):827834 .

17. Kojima G, Bell C, Tamura B, et al. Reducing cost by reducing polypharmacy: The polypharmacy outcomes project. J Am Med Dir Assoc. 2012;13(9):818.e811-818.e815.

18. ACGME, ABIM. The internal medicine subspecialty milestones project. 2014; https://www.americangeriatrics.org/sites/default/files/inlinefiles/Internal_Medicine_Subspecialty_Milestones.pdf. Accessed 12/21/ 2018.

19. Rugen K, Speroff E, Zapatka S, Brienza R. Veterans Affairs interprofessional nurse practitioner residency in primary care: a competency-based program. J Nurse Pract. 2016;12(6):e267-e273.

20. Williams BC, Warshaw G, Fabiny AR, et al. Medicine in the 21 st century: recommended essential geriatrics competencies for internal 
medicine and family medicine residents. J Grad Med Educ. 2010;2(3):373-383.

21. Keijsers CJ, van Hensbergen $\mathbf{L}$, Jacobs L, et al. Geriatric pharmacology and pharmacotherapy education for health professionals and students: a systematic review. Br J Clin Pharmacol. 2012;74(5):762-773.

22. Leipzig RM, Hall WJ, Fried LP. Treating our societal scotoma: the case for investing in geriatrics, our nation's future, and our patients. Ann Intern Med. 2012;156(9):657-659.

23. Institute of Medicine Committee on the Future Health Care Workforce for Older Americans. Retooling for an Aging America: Building the Health Care Workforce. Washington DC: National Academies Press (US); 2008.

24. Warshaw GA, Thomas DC, Callahan EH, et al. A National Survey on the Current Status of General Internal Medicine Residency Education in Geriatric Medicine. J Gen Intern Med. 2003;18(9):679-684.

25. Warshaw GA, Bragg EJ, Thomas DC, Ho ML, Brewer DE. Are internal medicine residency programs adequately preparing physicians to care for the baby boomers? A national survey from the Association of Directors of Geriatric Academic Programs Status of Geriatrics Workforce Study. J Am Geriatr Soc. 2006;54(10):1603-1609.

26. Bragg EJ, Warshaw GA, Arenson C, Ho ML, Brewer DE. A national survey of family medicine residency education in geriatric medicine: comparing findings in 2004 to 2001. Fam Med. 2006;38(4):258-264.

27. Drickamer MA, Levy B, Irwin KS, Rohrbaugh RM. Perceived needs for geriatric education by medical students, internal medicine residents and faculty. J Gen Intern Med. 2006;21(12):1230-1234.

28. Kostas $\mathbf{T}$, Zimmerman $\mathbf{K}$, Salow $\mathbf{M}$, et al. Improving medication management competency of clinical trainees in geriatrics. J Am Geriatr Soc. 2014;62(8):1568-1574.

29. Armstrong E, Parsa-Parsi R. How can physicians' learning styles drive educational planning? Acad Med. 2005;80(7):680-684.

30. Kolb D. Experiential learning: Experience as the source of learning and development. Englewood Cliffs, NJ: Prentice Hall; 1984.

31. Mecca M, Niehoff $\mathbf{K}$, Grammas M. Medication Review Worksheet 2015 2015. https://pogoe.org/productid/21872. Accessed 12/21/2018.

32. O'Mahony D, O'Sullivan D, Byrne S, O'Connor MN, Ryan C, Gallagher P. STOPP/START criteria for potentially inappropriate prescribing in older people: version 2. Age Ageing. 2015;44(2):213-218.

33. Hanlon JT, Semla TP, Schmader KE. Alternative Medications for Medications in the Use of High-Risk Medications in the Elderly and Potentially Harmful Drug-Disease Interactions in the Elderly Quality Measures. J Am Geriatr Soc. 2015;63(12):e8-e18.

34. By the American Geriatrics Society Beers Criteria Update Expert P. American Geriatrics Society 2015 Updated Beers Criteria for Potentially Inappropriate Medication Use in Older Adults. J Am Geriatr Soc. 2015;63(11):2227-2246.

35. Steinman MA, Beizer JL, DuBeau CE, Laird RD, Lundebjerg NE Mulhausen P. How to Use the American Geriatrics Society 2015 Beers Criteria-A Guide for Patients, Clinicians, Health Systems, and Payors. J Am Geriatr Soc. 2015;63(12):e1-e7.
36. Hanlon JT, Schmader KE, Samsa GP, et al. A method for assessing drug therapy appropriateness. J Clin Epidemiol. 1992;45(10):1045-1051.

37. Standards of medical care in diabetes-2014. Diabetes Care. 2014;37 Suppl 1:S14-80.

38. James PA, Oparil S, Carter BL, et al. 2014 evidence-based guideline for the management of high blood pressure in adults: report from the panel members appointed to the Eighth Joint National Committee (JNC 8). JAMA. 2014;311(5):507-520.

39. Stone NJ, Robinson JG, Lichtenstein AH, et al. 2013 ACC/AHA guideline on the treatment of blood cholesterol to reduce atherosclerotic cardiovascular risk in adults: a report of the American College of Cardiology/American Heart Association Task Force on Practice Guidelines. J Am Coll Cardiol. 2014;63(25 Pt B):2889-2934.

40. Moreno G, Mangione CM, Kimbro L, Vaisberg E. Guidelines abstracted from the American Geriatrics Society Guidelines for Improving the Care of Older Adults with Diabetes Mellitus: 2013 update. J Am Geriatr Soc. 2013;61(11):2020-2026.

41. McAuley D. Multiple Creatinine Clearance Methods. https://globalrph. $\mathrm{com} / \mathrm{medcalcs} / \mathrm{creatinine-clearance-multi-calc-2012-edition/,} 2018$. Accessed 12/21/2018.

42. ASCVD Risk Estimator Plus. http://tools.acc.org/ASCVD-Risk-Estimator-Plus/\#!/calculate/estimate/, 2018. Accessed 12/21/2018.

43. Hwang C. CHA2DS2-VASc score for atrial fibrillation stroke risk. http:// www.mdcalc.com/cha2ds2-vasc-score-for-atrial-fibrillation-stroke-risk/, 2015. Accessed 12/21/2018.

44. Bleeding Risk in Atrial Fibrillation: HAS-BLED Score. https://qxmd. com/calculate/calculator_106/bleeding-risk-in-atrial-fibrillation-hasbled-score, 2018. Accessed 12/21/2018.

45. Mecca M, Niehoff K. IMPROVE Polypharmacy Project. 2017; http:// improvepolypharmacy.yale.edu/. Accessed 12/21/2018.

46. Tariq SH, Tumosa N, Chibnall JT, Perry MH 3rd, Morley JE Comparison of the Saint Louis University mental status examination and the mini-mental state examination for detecting dementia and mild neurocognitive disorder-a pilot study. J Geriatr Psychiatry. 2006; 14(11):900-910.

47. Thomas J, Mecca M, Niehoff $\mathbf{K}$, et al. Development and validation of a polypharmacy knowledge assessment instrument. Am J Pharm Educ. 2017. http://www.ajpe.org/doi/pdf/10.5688/ajpe6435. Accessed 12/ 21/2018.

48. Bradley EH, Curry LA, Devers KJ. Qualitative data analysis for health services research: developing taxonomy, themes, and theory. Health Sery Res. 2007;42(4):1758-1772.

49. Fried TR, McGraw S, Agostini JV, Tinetti ME. Views of older persons with multiple morbidities on competing outcomes and clinical decisionmaking. J Am Geriatr Soc. 2008;56(10):1839-1844.

Publisher's Note Springer Nature remains neutral with regard to jurisdictional claims in published maps and institutional affiliations. 